cation, and price per issue or per annum. Available at $\$ 15$ net postpaid, from R. R. Bowker Company, 1180 Avenue of the Americas, New York, N.Y. 10036.

\section{SUGGESTIONS, ANYONE?}

The ACRL Committee on Appointments (1968) and Nominations (1969) wishes to solicit suggestions for appointments to ACRL committees for 1968/69. ACRL's success or failure during the year will depend to a large extent on these appointments.

Therefore, we urge you to submit the names of members who would make significant contributions to the work of ACRL through committee appointment. As the number of appointments to be made is limited, it is important that the best possible appointments be made.

Members of the Committee on Appointments (1968) and Nominations (1969) include Ben C. Bowman, Jane G. Flener, Harriett Genung, Marcus A. McCorison, Carl H. Sachtleben, Mrs. Jessie Carney Smith and Howard Rovelstad, chairman.

Kindly send your recommendations of prospective appointees to the following ACRL committees to the undersigned:

Join the

AMERICAN LIBRARY ASSOCIATION

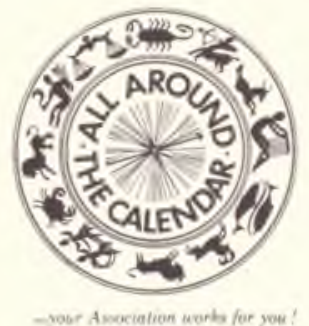

MeMachaหir pMomotion MMCRICAN LIERART ASSOCBATION So CAST HUaON STREeT
Audio-Visual Committee

Committee on Community Use of Academic Libraries

Advisory Committee on Cooperation with Educational and Professional Organizations

Committee on Grants

International Relations Committee

Committee on Legislation

Committee on Liaison with Accrediting Agencies

Committee on Library Services

Committee on Library Surveys

National Library Week Committee

Planning and Action Committee

Publications Committee

Committee on Standards

Recommendations should be sent to the undersigned by November 15 .

Howard Rovelstad, Chairman

ACRL Committee on Appointments (1968) and Nominations (1969)

University of Maryland Libraries College Park, Maryland 20740

\section{AN APPRECIATION \\ (Continued from page 223)}

subject-centered bibliographic articles, has contributed such selection aids as the "Opening Day Collection," and, according to the response from subscribers, has filled a void in current reviewing of academic books. It has proved useful to public, junior college, secondary school, special, and foreign libraries.

CHOICE promises to provide continuing evaluation of new books; but it is also considering the publication of supplements to Books for College Libraries, and is moving toward reviewing U.S. Government documents and foreign publications.

CHOICE is essentially the product of the intelligence, determination, and courage of Verner Clapp and members of the Council on Library Resources. Because of their support and advice, librarians and libraries are benefiting. Both the Council and Verner Clapp have eschewed interference with editorial policy, placing confidence in the Association of College and Research Libraries, which in turn, has intrusted the policy-making to an editorial board. The Association appreciates the Council's further commitment to CHOICE in the form of a three-year grant renewal for $\$ 108,855$. Such confidence merits increased service to libraries by the Association and the editorial staff of CHOICE. 


\section{The Encyclopedia of Philosophy is the only reference work of its kind in the English language.}

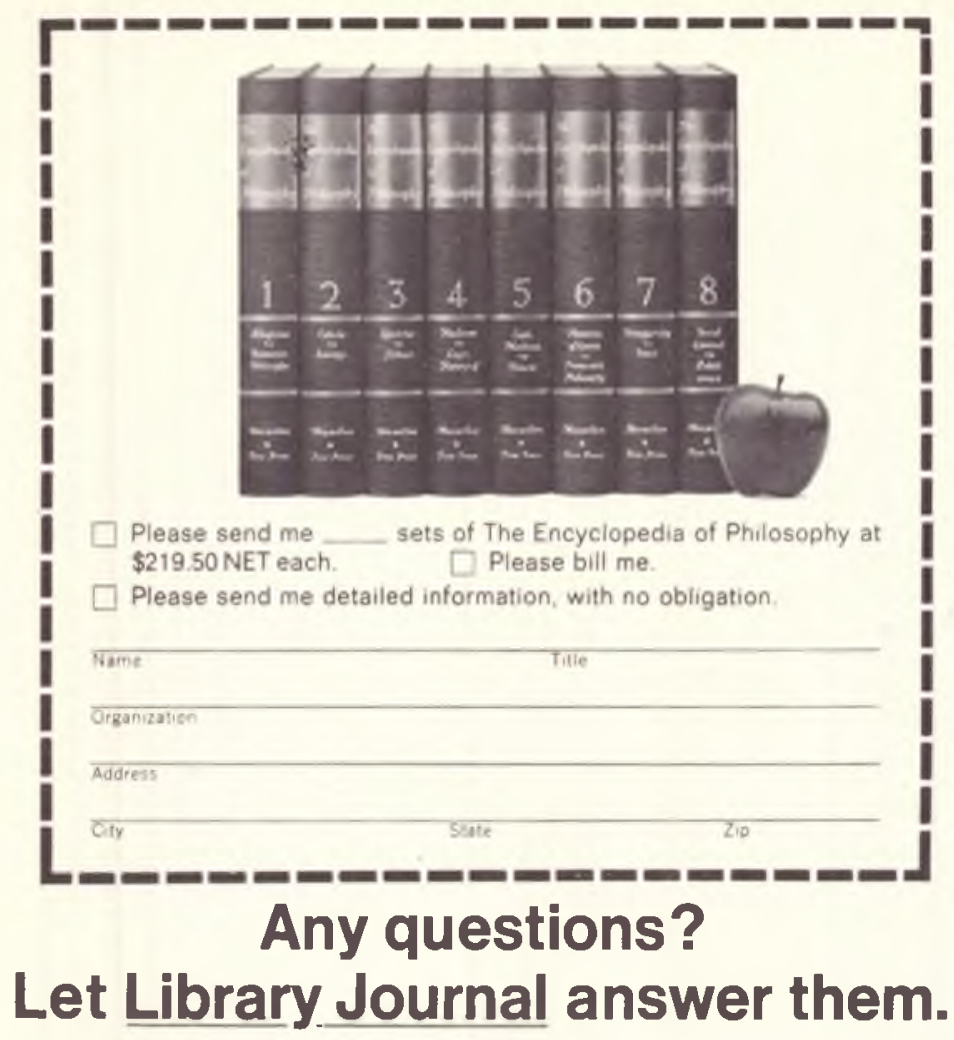

How complete is it?

Library Journal says: ". . . the 'reference gap' for philosophy has been bridged in a most impressive manner."

"The 1450 signed artjcles are comprehensive in scope and treatment."

How reliable is it?

Library Journal says: "The roster of 500 contributors from 24 countries reads like an international who's who of philosophy and cultural history."

\section{Is it culturally objective?}

Library lournal says: "Oriental philosophy is covered as thoroughly and authoritatively as our own Western traditions; ancient and medieval philosophers receive a coverage at least equal to that of contemporary thinkers."

Is it both scholarly and stimulating?

Library Journal says: "The manner of presentation is orderly, logical and authoritative."

"... the Encyclopedia of Philosophy is characterized by a lively style and large attractive print that should delight public library patrons as much as university professors."

Is it simple to use?

Library Journal says: "A detailed, easy-to-use subject index greatly enhances the usefulness of this set for nonspecialists.'

Does it do justice to "borderline" subjects? Library Journal says: ". . . students of science will find references to technical articles..."

"Reference librarians will welcome the exhaustive article on 'Philosophical Dictionaries and Encyclopedias' ... and another on 'Philosophical Journals'..."

Who should use The Encyclopedia of Philosophy? Library Journal says: "Because of its broad coverage and sound scholarship, this encyclopedia is strongly recommended for college, university, and all but the smallest public libraries."

All quotes taken from the issue dated April 15, 1967.

\section{Collier-Macmillan Library Services}

866 Third Avenue, New York, New York 10022 


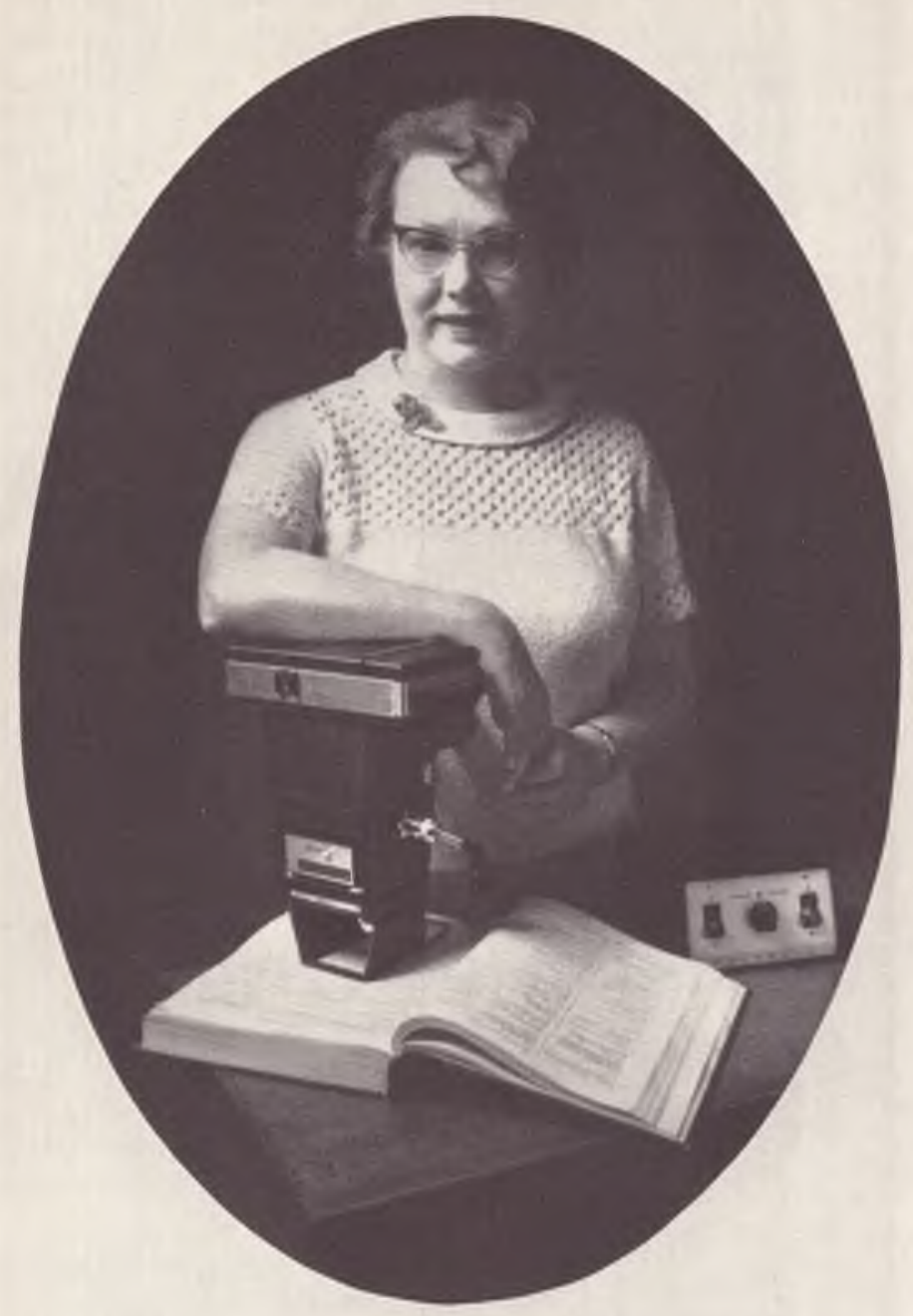

Helen Oustinoff.

She found a way to order

and process books faster with

the Polaroid CU-5 Camera. 
Helen Oustinoff is Assistant Director of the University of Vermont Library. She has developed a remarkable new system for processing books, utilizing our Polaroid CU.5 Close-up Land Camera.

\section{No more checking or transcribing}

Here's how her system works: When a book purchase request slip is received, the searcher looks up the book in the National Union Catalog or another standard bibliog. raphy. Just as always. But she doesn't bother to correct or complete the slip. She simply photographs the entire N.U.C. entry with the CU-5 Camera.

We make that sound very easy. It is. You just center the CU.5's frame over the entry and squeeze the trigger. Pull the tabs and 15 seconds later you have an enlarged print of the whole thing. (Like the one below.) Isn't that easier than copying by hand? And faster? And more accurate?

\section{No handwriting to decipher}

Now the book order slip is typed from the Polaroid print. And the print is then filed away with a carbon of the typed order.
If the original entry happens to be in He. brew, or something else untypable, you can simply shoot an extra print and send it along with the order.

When the book is received, it's checked against the print and the invoice is cleared.

\section{No waiting for catalog cards}

Who needs preprinted catalog cards? With this new system, you make your own. Using the Polaroid print as a guide, you can type them on an automatic typewriter. Or simply add necessary information to the print and run it through a copying machine.

The system also gets books into circulation faster because it eliminates waiting for preprinted cards. It also eliminates the job of ordering them. And the cost.

For more information about the time and cost saving features of this library system, write to: Polaroid Corporation, Dept. 113, Cambridge, Mass. 02139.

And if you have any suggestions as to new uses for our CU-5 Camera, send them along.

Who knows? You might be our next ad.

POLAROID CU-5 LIBRARY CAMERA

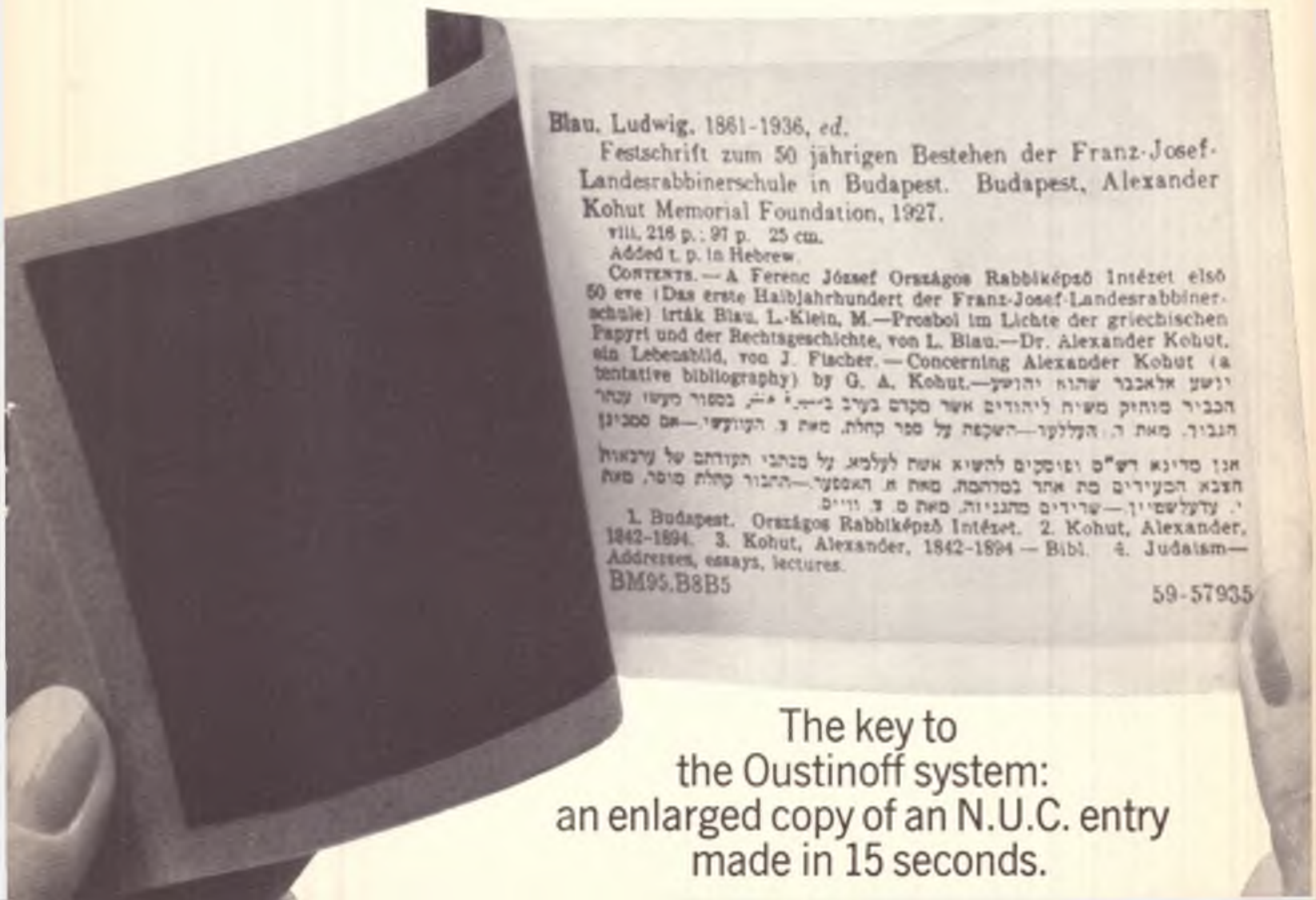

